\title{
Admission CT Perfusion Is an Independent Predictor of Hemorrhagic Transformation in Acute Stroke with Similar Accuracy to DWI
}

\author{
Leticia C.S. Souza ${ }^{a}$ Seyedmehdi Payabvash ${ }^{a}$ Yifei Wang ${ }^{c}$ Shervin Kamalian ${ }^{a}$ \\ Pamela Schaefer $^{a} \quad$ R. Gilberto Gonzalez ${ }^{a} \quad K^{2}$ aren L. Furie ${ }^{b} \quad$ Michael H. Lev ${ }^{a}$ \\ Departments of a Radiology and ${ }^{b}$ Neurology, Massachusetts General Hospital and Harvard Medical School, \\ Boston, Mass., USA; ' ${ }^{C}$ Schulich School of Medicine and Dentistry, University of Western Ontario, \\ London, Ont., Canada
}

\section{Key Words}

Stroke $\cdot$ Hemorrhagic transformation $\cdot$ CT scan $\cdot$ Perfusion

\begin{abstract}
Background: The utility of admission CT perfusion (CTP) to that of diffusion-weighted imaging (DWI) as a predictor of hemorrhagic transformation (HT) in acute stroke was compared. Methods: We analyzed the admission CTP and DWI scans of 96 consecutive stroke patients. HT was present in 22 patients (23\%). Infarct core was manually segmented on the admission DWI. We determined the: (1) hypoperfused tissue volume in the ischemic hemisphere using a range of thresholds applied to multiple different CTP parameter maps, and (2) mean relative CTP ( $\mathrm{rCTP}$ ) voxel values within both the DWI-segmented lesions and the thresholded CTP parameter maps. Receiver operating characteristic area under curve (AUC) analysis and multivariate regression were used to evaluate the test characteristics of each set of volumes and mean rCTP parameter values as predictors of HT. Results: The hypoperfused tissue volumes with either relative cerebral blood flow $(\mathrm{rCBF})<0.48(\mathrm{AUC}=0.73)$, or relative mean transit time $(\mathrm{rMTT})>1.3(\mathrm{AUC}=0.70)$, had similar accuracy to the DWI-segmented core volume $(A \cup C=0.68, p=0.2$ and $p=$ 0.1 , respectively) as predictors of $\mathrm{HT}$. The mean rMTT voxel
\end{abstract}

values within the rMTT $>1.3$ segmented lesion $(A \cup C=0.71)$ had similar accuracy to the mean rMTT voxel values (AUC $=$ $0.65, p=0.24$ ) and mean $r C B F$ voxel values (AUC $=0.64, p=$ 0.22 ) within the DWI-segmented lesion. The only independent predictors of HT were: (1) mean rMTT with rMTT $>1.3$, and (2) mechanical thrombectomy. Conclusion: Admission CTP-based hypoperfused tissue volumes and thresholded mean voxel values are markers of $\mathrm{HT}$ in acute stroke, with similar accuracy to DWI. This could be of value when MRI cannot be obtained.

Copyright $\odot 2011$ S. Karger AG, Basel

\section{Introduction}

Hemorrhagic transformation (HT) is an unwanted complication of ischemic stroke that may severely worsen prognosis. Many studies have tried to determine clinical and imaging parameters associated with $\mathrm{HT}$ so as to identify patients at highest risk for thrombolytic or endovascular therapies. These studies have found infarct-core volume on admission diffusion-weighted imaging (DWI) scans to be an independent predictor of HT [1]. Other variables that have been correlated with $\mathrm{HT}$ include low mean apparent diffusion coefficient (ADC) [1], large ves-

\section{KARGER}

(C) 2011 S. Karger AG, Basel

Fax +41613061234 E-Mail karger@karger.ch www.karger.com www.karger.com/ced
Michael H. Lev, MD

Department of Radiology, GRB285

Massachusetts General Hospital, PO Box 9657

Boston, MA 02114-9657 (USA)

Tel. +1 617724 7125, E-Mail mlev@ partners.org 
Table 1. Demographics of patients not included in the study

\begin{tabular}{lll}
\hline $\begin{array}{l}\text { Patients not in the study } \\
(\mathrm{n}=57)\end{array}$ & $\begin{array}{l}\text { Hemor- } \\
\text { rhage }(\%)\end{array}$ & $\begin{array}{l}\text { No hemor- } \\
\text { rhage }(\%)\end{array}$ \\
\hline $\begin{array}{l}\text { Number of cases } \\
\text { Patients demographics }\end{array} \quad 16(25)$ & $41(68)$ \\
$\quad$ Mean age & 70 & 71 \\
$\quad$ Female & $11(69)$ & $19(46)$ \\
$\quad$ Male & $5(30)$ & $22(53)$ \\
$\begin{array}{l}\text { Clinical characteristics } \\
\quad \text { Mean admission NIHSS }\end{array}$ & 14 & 15.13 \\
$\begin{array}{l}\text { Imaging findings } \\
\quad \text { DWI lesion volume }\end{array}$ & 53.0 & 34.2 \\
$\quad \begin{array}{l}\text { Large vessel occlusion (BASIS) } \\
\text { Treatment modalities } \\
\quad \text { tPA }\end{array}$ & $9(69)$ & $31(75)$ \\
\hline
\end{tabular}

There was a similar incidence of HT and similar demographics in those patients excluded from our study due to incomplete datasets.

sel circle of Willis occlusion [2], low attenuation [3] or poor collateral vessels [4] on CT angiography (CTA) source images, and signs of blood-brain barrier disruption such as increased CT perfusion (CTP) and MR perfusion permeability values [3-5], MRI hyperintense acute injury marker sign [6], and reduced cerebral blood volume (CBV) or flow (CBF) $[7,8]$.

Multiple studies have suggested that HT results from reperfusion into a large volume of severely ischemic tissue [9]. Flow measures might therefore be useful to identify ischemic tissue at risk of HT. Indeed, Ueda et al. [10] demonstrated an increased likelihood of HT in ischemic brain with more than $65 \% \mathrm{CBF}$ reduction. In patients with middle cerebral artery (MCA) occlusion, ischemic tissue with a mean CBF ratio $<0.18$ is more likely to hemorrhage [9]. Low or completely absent contrast arrival in cerebral perfusion scans has been reported to reflect tissue at risk for HT [11].

The aim of our study was therefore to compare the utility of admission CTP to that of DWI as a predictor of HT of acute stroke. CTP-based risk markers have the potential to substitute for DWI when the latter is not available. Imaging variables we studied included CTA-defined arterial occlusion, recanalization following endovascular treatment, DWI lesion volumes, and CTP parameter map volumes and thresholded voxel values. Clinical variables included admission NIH stroke scale (NIHSS) score, time elapsed from ictus to hospital admission, and the use of thrombolytic or mechanical endovascular therapies.

\section{Methods}

\section{Patients}

We retrospectively reviewed the medical records and imaging data of 153 consecutive patients with acute ischemic stroke who were admitted to our emergency department between April 2008 and May 2009. All patients had admission NIHSS scores recorded and underwent our routine stroke imaging protocol. Inclusion criteria for imaging evaluation consisted of a non-contrast CT (NCCT) of the head, CTA of the head, neck, and arch, CTP with $8-\mathrm{cm}$ anterior circulation coverage (shuttle mode), MRI-DWI within $9 \mathrm{~h}$ of symptom onset, and a follow-up scan (NCCT or MRI) within the following 5 days for HT evaluation. Ninety-six patients had a complete set of images and were included in our study. The 57 excluded patients had a similar incidence of HT and demographics compared to the study cohort (table 1). Patients were treated according to standard institutional protocols, including intravenous (IV) thrombolysis or intra-arterial (IA) therapy as clinically indicated [12].

Our institutional review board approved our retrospective review of all medical and imaging data.

\section{Image Acquisition}

CT imaging was performed using a helical scanner (LightSpeed 64; GE Medical Systems, Milwaukee, Wisc., USA) in the emergency department. NCCT scans were performed in helical mode $(1.25 \mathrm{~mm}$ thickness, $120 \mathrm{kV}, 250 \mathrm{~mA})$. CTA was performed during the administration of $80 \mathrm{ml}$ of non-ionic contrast agent (Omnipaque 370; Nycomed Inc., Roskilde, Denmark) followed by $40 \mathrm{ml}$ of saline, both at a rate of $4 \mathrm{ml} / \mathrm{s}$, from the aortic arch to vertex $(1.25 \mathrm{~mm}$ thickness, $120 \mathrm{kV}, 350-800 \mathrm{~mA}, 0.5-0.7$ s/rotation). CTP was acquired using shuttle perfusion mode during administration of $35 \mathrm{ml}$ of non-ionic contrast $(7 \mathrm{ml} / \mathrm{s})$ followed by $40 \mathrm{ml}$ of saline $(4 \mathrm{ml} / \mathrm{s})$ (time of acquisition $91 \mathrm{~s}, 80 \mathrm{kV}, 500 \mathrm{~mA}$ ), providing 16 slices with $5 \mathrm{~mm}$ thickness ( $8 \mathrm{~cm}$ coverage); total radiation exposure was $<500 \mathrm{mGy}$. Perfusion images were postprocessed using GE's software CTP3. Using the protocol described above, the total estimated effective radiation dose was approximately $14.2 \mathrm{mSv}$ (NCCT $2.0 \mathrm{mSv}$, CTA $4.3 \mathrm{mSv}$, and CTP $7.9 \mathrm{mSv}$ ).

MR scans were performed on a $1.5 \mathrm{~T}$ Signa whole-body scanner (GE Medical Systems). TR was 5,000 ms; TE was minimum (typically $85-110 \mathrm{~ms}$ ). Isotropic admission DWI and ADC maps were reviewed, as well as follow-up GRE T2* susceptibility sequences.

\section{Image Analysis}

All images were analyzed by a radiologist with 5 years of general and 1 year of dedicated neuroradiology experience (L.C.S.S.), blinded to the patients' clinical histories, and follow-up imaging. Admission images were assessed for stroke laterality and the presence of target large vessel occlusion (LVO) on CTA, according to the Boston Acute Stroke Imaging Scale (BASIS) criteria [13]. LVO was defined as occlusion of the terminal internal carotid artery, proximal MCA (M1 or M2), and/or the basilar artery. Follow-up scans were assessed for the presence of HT. The follow-up scans included NCCT in 70\% (67/96) of cases and MR in the remaining $30 \%$ (29/96). Of those patients with HT, $40 \%(8 / 22)$ had MRI and $60 \%(14 / 22)$ had NCCT as their follow-up. Any new hemorrhage on follow-up was considered HT, collapsing the European Coop- 
erative Acute Stroke Study I (ECASS I) classification system [14] into a single category.

Recanalization was determined in the subset of patients who received IA therapy, and in those who had a follow-up CTA or MRA, for vascular patency assessment. In those who underwent IA therapy, a TICI score of $2 \mathrm{a}$ or higher was considered recanalization. On non-invasive imaging, recanalization was defined as complete luminal opacification of previously occluded vessels.

For each patient, the volume of infarction was manually segmented on the admission DWI based on visual qualitative assessment of both the DWI and ADC images, using a commercial image analysis software (L.S.) (Analyze 8.1, AnalyzeDirect; Mayo Clinic, Rochester, Minn., USA). All MRI-DWI, CTP scans, and the DWI outlined lesions were automatically co-registered to the MNI-152 template using the Linear Image Registration Tool (FLIRT5.5; Oxford Centre for Functional Magnetic Resonance Imaging of the Brain, Oxford, UK). On a voxel-by-voxel basis, relative $\mathrm{CBF}$ ( $\mathrm{rCBF}), \mathrm{CBV}$ ( $\mathrm{rCBV})$, mean transit time (rMTT), and permeability surface (rPS) values were calculated as the ratio of absolute voxel values in the ischemic hemisphere to corresponding, contralateral mirror voxels, using a custom-made software program (Y.W.) (MatLab7.8; The MathWorks, Natick, Mass., USA). First, we used the resulting CTP parameter maps (consisting of relative voxel values on the ischemic hemisphere) to examine the performance of the hypoperfused CTP lesion volumes in determining HT. Specifically, we determined the volume of the ischemic lesions with $\mathrm{rCBF}$ and $\mathrm{rCBV}$ voxel values below thresholds ranging from 0.1 to 0.7 at 0.02 intervals, as well as those with rMTT and rPS above thresholds ranging from 1.3 to 2.8 at 0.05 intervals. Next, the mean rCTP parameter voxel values within the hypoperfused lesion volumes were calculated for the thresholds that optimally determined HT. The mean rCTP voxel values within the infarct core - segmented admission DWI lesions were also determined.

\section{Statistical Analysis}

Patients were stratified into two groups based on the follow-up scan: those with HT versus those without HT ('HT'vs. 'non-HT').

Receiver operator characteristic (ROC) curves were generated for the DWI and thresholded CTP lesion volumes to determine and compare their individual test characteristics in distinguishing HT from non-HT patients, including area under curve (AUC), sensitivity and specificity. The CTP threshold with the highest AUC was selected for each parameter map (CBF, BCV, MTT and rPS).

We performed univariate analyses to compare the imaging and clinical variables between these two groups. We used Student's t test (variables with normal distribution), Mann-Whitney rank test (variables without a normal distribution), and $\chi^{2}$ (categorical variables).

Using those clinical and CT-based imaging variables that were significant in the univariate analyses, we determined the independent predictors of HT using multivariate binary logistic regression modeling (thresholds for inclusion/exclusion of variables were $\mathrm{p} \leq 0.05$ and $\mathrm{p} \geq 0.1$, respectively). We have additionally performed univariate and multivariate analyses after stratification according to time elapsed from ictus to scanning ( $\leq 4.5 \mathrm{vs.}$ $>4.5 \mathrm{~h}$ ). ROC curves were generated to evaluate each significant variable's test characteristics in distinguishing HT from non-HT.
STATA 10 (Stata Corp., College Station, Tex., USA) and SPSS 17.0 (SPSS Inc., Chicago, Ill., USA) software were used to perform the statistical analyses. All values are expressed as either mean $\pm \mathrm{SE}$, median (interquartile, IQ), or number (percentage), to the $\mathrm{p}<$ 0.05 level of significance.

\section{Results}

Ninety-six patients were included in our analysis. Of these, 22 (23\%) had HT on follow-up scan. Of the 22 hemorrhage cases, 3 were classified as parenchymal hematomas (PH) and 19 as hemorrhagic infarctions (HI); there were insufficient $\mathrm{PH}$ cases to stratify for subgroup analysis. A detailed list of the characteristics of the patients with hemorrhage is shown in table 2.

The median ictus to CTP interval was $3.9 \mathrm{~h}$ (IQ 2-5), and the median CTP to DWI interval was $57 \mathrm{~min}$ (IQ 41-78).

\section{CTP versus DWI}

In the ROC curve analysis, DWI-based infarct volume had an AUC of 0.68 ( $p<0.01)$ for determining HT. At an admission infarct volume of $100 \mathrm{ml}$ (the operating point of the ROC curve), there was 51\% specificity and $91 \%$ sensitivity. The Mann-Whitney test showed a significant difference between the median infarct volumes of the two groups (33 ml (IQ 15-74) for HT and $10 \mathrm{ml}$ (IQ 4-48) for non-HT, $\mathrm{p}=0.01)$.

For CTP, the hypoperfused volumes in the ischemic hemisphere that optimally determined HT were obtained at thresholds of $\mathrm{rCBF} \leq 0.48$ and $\mathrm{rMTT} \geq 1.3$, with AUCs of $0.73(\mathrm{p}=0.03)$ and $0.70(\mathrm{p}=0.04)$, respectively. There was no significant difference between the DWI and the CTP-based volumes in distinguishing HT from non-HT ( $\mathrm{p}=0.21$ vs. $\mathrm{rCBF}$, and $\mathrm{p}=0.10$ vs. rMTT). For $\mathrm{rCBF}$ $\leq 0.48$, at an optimal operating point threshold volume of $43 \mathrm{ml}$, there was $86 \%$ sensitivity and 53\% specificity. For $\mathrm{rMTT} \geq 1.3$, at an optimal operating point threshold volume of $87 \mathrm{ml}$, there was $82 \%$ sensitivity and $60 \%$ specificity. The AUCs for both rCBV and rPS ROC curves were $<0.6$ for determining HT, therefore these CTP parameters were excluded from further multivariate analysis. The average volumes of hypoperfused brain based on the $\mathrm{rCBF} \leq 0.48$ and $\mathrm{rMTT} \geq 1.3$ thresholds were significantly higher in patients with $\mathrm{HT}$ versus those without $(75.2 \pm 6.9$ vs. $53.6 \pm 5.0 \mathrm{ml}, \mathrm{p}=0.03$, and $120.4 \pm 10.0$ vs. $89.5 \pm 6.9 \mathrm{ml}, \mathrm{p}=0.04$, respectively).

The mean $\mathrm{rCBF}$ and rMTT values within the DWIsegmented infarct core were significantly different be- 
Table 2. Hemorrhagic transformation cases characteristics

\begin{tabular}{|c|c|c|c|c|c|c|c|c|c|c|c|c|c|c|c|c|}
\hline HT & Age & Sex & $\begin{array}{l}\text { DWI } \\
\text { vol, ml }\end{array}$ & $\begin{array}{l}0.48 \mathrm{CBF} \\
\text { vol, } \mathrm{ml}\end{array}$ & $\begin{array}{l}1.3 \mathrm{MTT} \\
\text { vol, } \mathrm{ml}\end{array}$ & $\begin{array}{l}\text { Mean rMTT } \\
\text { of } 1.3 \text { MTT } \\
\text { lesion }\end{array}$ & $\begin{array}{l}\text { IV } \\
\text { t-PA }\end{array}$ & $\begin{array}{l}\text { Mechan- } \\
\text { ical throm- } \\
\text { bectomy }\end{array}$ & $\begin{array}{l}\text { Recana- } \\
\text { lization }\end{array}$ & $\begin{array}{l}\text { Symp- } \\
\text { tomatic }\end{array}$ & $\begin{array}{l}\text { Ictus - } \\
\text { CTP } \\
\text { interval }\end{array}$ & $\begin{array}{l}\text { CTP - } \\
\text { DWI } \\
\text { interval }\end{array}$ & $\begin{array}{l}\text { Ictus - } \\
\text { IV t-PA } \\
\text { interval }\end{array}$ & $\begin{array}{l}\text { Ictus - } \\
\text { intervention } \\
\text { interval }\end{array}$ & $\begin{array}{l}\text { Interven- } \\
\text { tion - HT } \\
\text { interval }\end{array}$ & $\begin{array}{l}\text { Ictus-recan- } \\
\text { alization } \\
\text { interval }\end{array}$ \\
\hline HI1 & 51 & $\mathrm{~F}$ & 67.7 & 102.4 & 132.8 & 4.1 & Yes & Yes & Yes & No & $5: 30$ & $0: 36$ & $1: 30$ & $8: 52$ & $14: 55$ & $10: 20$ \\
\hline HI1 & 43 & M & 20.7 & 67.1 & 113.3 & 3.4 & No & No & No & No & $5: 50$ & 4:01 & N/A & N/A & N/A & N/A \\
\hline HI1 & 79 & $\mathrm{~F}$ & 7.8 & 26.2 & 59.5 & 3.2 & No & No & Yes & No & 5:00 & $0: 37$ & N/A & N/A & N/A & - \\
\hline HI1 & 84 & $\mathrm{M}$ & 50.0 & 66.7 & 113.6 & 3.8 & Yes & No & No & No & $4: 28$ & $1: 10$ & $2: 45$ & N/A & N/A & N/A \\
\hline HI1 & 37 & F & 11.2 & 43.4 & 28.4 & 5.4 & No & Yes & Yes & No & $8: 13$ & $0: 27$ & N/A & $10: 35$ & $17: 30$ & $8: 39$ \\
\hline HI1 & 37 & $\mathrm{~F}$ & 11.2 & 30.1 & 66.4 & 4.4 & No & Yes & Yes & No & $8: 10$ & $0: 25$ & N/A & $10: 20$ & $17: 20$ & $8: 30$ \\
\hline HI1 & 58 & $\mathrm{M}$ & 92.7 & 93.3 & 152.3 & 3.8 & No & No & No & No & $3: 58$ & $0: 50$ & N/A & N/A & N/A & N/A \\
\hline HI1 & 62 & $\mathrm{M}$ & 31.9 & 139.3 & 221.1 & 3.1 & No & No & - & No & 1:09 & $1: 11$ & N/A & N/A & N/A & - \\
\hline HI1 & 60 & M & 24.7 & 83.8 & 131.1 & 4.0 & Yes & Yes & No & No & $3: 15$ & $0: 54$ & $1: 50$ & $7: 29$ & $17: 36$ & N/A \\
\hline HI2 & 54 & M & 75.0 & 106.7 & 168.0 & 3.0 & No & Yes & Yes & No & $4: 57$ & $0: 23$ & $\mathrm{~N} / \mathrm{A}$ & $7: 58$ & 4:09 & 9:09 \\
\hline HI2 & 59 & $\mathrm{M}$ & 34.8 & 85.5 & 164.2 & 3.5 & No & No & - & No & 1:00 & $4: 26$ & N/A & N/A & N/A & - \\
\hline HI2 & 77 & $\mathrm{~F}$ & 128.8 & 118.7 & 196.6 & 4.3 & Yes & No & No & Yes & 4:50 & $0: 55$ & 2:00 & N/A & N/A & N/A \\
\hline HI2 & 70 & $\mathrm{M}$ & 73.6 & 62.1 & 160.8 & 5.4 & No & No & No & Yes & 7:00 & 1:04 & N/A & N/A & N/A & N/A \\
\hline HI2 & 48 & $\mathrm{M}$ & 10.4 & 57.4 & 99.6 & 3.1 & Yes & Yes & Yes & No & $0: 27$ & $0: 27$ & 1:05 & $3: 18$ & $0: 36$ & $4: 52$ \\
\hline HI2 & 85 & $\mathrm{~F}$ & 135.1 & 44.6 & 106.0 & 3.7 & Yes & No & Yes & No & $3: 50$ & 2:01 & $1: 44$ & N/A & N/A & - \\
\hline HI2 & 52 & M & 20.2 & 115.4 & 100.5 & 3.8 & No & Yes & Yes & No & $3: 38$ & $0: 44$ & $\mathrm{~N} / \mathrm{A}$ & $6: 20$ & $1: 06$ & $8: 30$ \\
\hline HI2 & 74 & $\mathrm{M}$ & 49.1 & 65.4 & 99.8 & 2.7 & Yes & No & - & No & 2:00 & $1: 10$ & $1: 35$ & N/A & N/A & - \\
\hline HI2 & 82 & $\mathrm{~F}$ & 2.6 & 36.6 & 72.0 & 3.1 & Yes & Yes & No & Yes & $4: 50$ & $0: 50$ & $1: 51$ & $6: 50$ & $12: 46$ & N/A \\
\hline HI2 & 77 & $\mathrm{M}$ & 107.3 & 128.6 & 151.2 & 4.2 & Yes & No & - & Yes & $4: 20$ & $0: 45$ & $0: 33$ & N/A & N/A & - \\
\hline PH1 & 79 & F & 26.1 & 63.5 & 123.1 & 3.7 & No & No & - & Yes & $3: 38$ & $0: 47$ & N/A & N/A & N/A & - \\
\hline PH1 & 81 & $\mathrm{~F}$ & 38.5 & 52.6 & 99.6 & 3.7 & No & No & No & No & 1:50 & $0: 53$ & $\mathrm{~N} / \mathrm{A}$ & N/A & N/A & N/A \\
\hline PH2 & 55 & $\mathrm{M}$ & 16.0 & 65.0 & 89.4 & 3.9 & No & Yes & Yes & Yes & $4: 50$ & $5: 49$ & N/A & $7: 20$ & $1: 37$ & $9: 33$ \\
\hline
\end{tabular}

tween the HT and non-HT groups $(0.44 \pm 0.03$ vs. 0.57 $\pm 0.03, \mathrm{p}=0.02$ for $\mathrm{rCBF}$, and $3.08 \pm 0.22$ vs. $2.48 \pm$ $0.10, p=0.01$ for $\mathrm{rMTT}$, respectively). Likewise, the mean rMTT within the MTT-segmented lesion ( $\mathrm{rMTT}>1.3$ ) was significantly different between the HT and non-HT groups $(2.78 \pm 0.61$ vs. $2.30 \pm 0.57, p=0.001)$. There was no significant difference between the AUCs of these parameters (rMTT within the MTT-segmented lesion AUC $=0.71$ vs. $r M T T$ within the DWI-segmented lesion, $\mathrm{AUC}=0.65, \mathrm{p}=0.24$, and vs. $\mathrm{rCBF}$ within the DWI-segmented lesion, $\mathrm{AUC}=0.64, \mathrm{p}=0.22$ ).

When patients were stratified according to time postictus at admission (early $=\leq 4.5 \mathrm{~h}$ post-ictus, late $=$ $>4.5 \mathrm{~h}$ post-ictus), for the early presentation group, those who developed HT had higher mean admission NIHSS score (11 \pm 7 vs. $17 \pm 4, \mathrm{p}=0.007)$, and larger median admission DWI lesion volume (36.6 vs. $12.8 \mathrm{ml}, \mathrm{p}=$ $0.024)$. Likewise, the average volumes of hypoperfused brain based on the $\mathrm{rCBF} \leq 0.48$ and $\mathrm{rMTT} \geq 1.3$ thresholds were significantly higher in patients with $\mathrm{HT}$ versus those without $(83.0 \pm 30.8$ vs. $53.6 \pm 31.5 \mathrm{ml}, \mathrm{p}=0.005$, and $130.2 \pm 36.8$ vs. $91.1 \pm 50.6 \mathrm{ml}, \mathrm{p}=0.006$, respectively). The mean rMTT values within the DWI-segmented infarct core $(3.1 \pm 0.8$ vs. $2.5 \pm 0.9, \mathrm{p}=0.04)$ and within the MTT-segmented lesion ( $\mathrm{rMTT}>1.3 ; 2.7 \pm 0.4$ vs. $2.3 \pm 0.6, \mathrm{p}=0.02$ ) were also higher for those who developed HT. For the late presentation patients, only mean rMTT within the MTT-segmented lesion (rMTT $>1.3$ ) was significantly different between the HT and non-HT groups $(3.2 \pm 1.0$ vs. $2.3 \pm 0.5, \mathrm{p}=0.017)$.

\section{Other Imaging and Clinical Variables Studied}

All patients with HT had a proximal LVO, whereas among the patients who did not bleed, 54 (69\%) had a LVO $(\mathrm{p}<0.01)$.

Treatment with either IV or IA thrombolytics had no effect on the incidence of HT. Of the 22 HT patients, 9 (41\%) received thrombolytic therapy (all IV), and of the 74 without $\mathrm{HT}, 35$ (48\%) received thrombolytic therapy (32 IV/3 IA) ( $p=0.50$ for IA $t-P A$, and $p=0.45$ for IV $\mathrm{t}-\mathrm{PA})$. IV and IA lysis were started at a mean time postictus of $1.8 \mathrm{~h}( \pm 0.6)$ and $7.1 \mathrm{~h}( \pm 2.8)$, respectively.

Mechanical thrombectomy increased the likelihood of bleeding by nearly four times (OR 3.7, 95\% CI 1.2-11.9, $\mathrm{p}<0.01) .9 / 22(41 \%)$ of the HT group were treated with mechanical thrombectomy, whereas $11 / 74(15 \%)$ of the non-HT group received the same treatment. On average, mechanical thrombectomy was initiated $6.4 \mathrm{~h}( \pm 2.5)$ after stroke onset and HT occurred $9.8 \mathrm{~h}( \pm 7.7)$ after the procedure.

For the 20 patients who underwent mechanical thrombectomy, the time from ictus to start of treatment was an 
Table 3. Univariate analysis

\begin{tabular}{|c|c|c|c|}
\hline & Hemorrhage & No hemorrhage & $\mathrm{p}$ value \\
\hline Number of patients & $22(23 \%)$ & $74(77 \%)$ & \\
\hline \multicolumn{4}{|l|}{ Patients demographics } \\
\hline Mean age & 64 & 68 & 0.23 \\
\hline Female gender & $9(40 \%)$ & $27(36 \%)$ & 0.80 \\
\hline \multicolumn{4}{|l|}{ Clinical characteristics } \\
\hline Mean admission NIHSS score & 16.5 & 10.9 & 0.001 \\
\hline Time from ictus (h:m) & $4: 14$ & $3: 42$ & 0.33 \\
\hline \multicolumn{4}{|l|}{ Imaging findings } \\
\hline Median DWI lesion volume (ml) & $33.3(14.8-73.9)$ & $10.3(4.3-48.5)$ & 0.011 \\
\hline Mean rCBF within DWI lesion & 0.44 & 0.57 & 0.02 \\
\hline Mean rCBV within DWI lesion & 0.91 & 0.97 & 0.28 \\
\hline Mean rMTT within DWI lesion & 3.09 & 2.48 & 0.01 \\
\hline Mean rPS within DWI lesion & 1.99 & 1.91 & 0.67 \\
\hline Volume of ischemic lesion with $\mathrm{rCBF}<0.48(\mathrm{ml})$ & 75.2 & 53.7 & 0.03 \\
\hline Volume of ischemic lesion with rMTT $>1.3(\mathrm{ml})$ & 120.4 & 89.5 & 0.04 \\
\hline Mean $\mathrm{rCBF}$ within ischemic lesion with $\mathrm{rCBF}<0.48$ & 0.269 & 0.289 & 0.06 \\
\hline Mean rMTT within ischemic lesion with $\mathrm{rMTT}>1.3^{\mathrm{a}}$ & 2.78 & 2.30 & 0.001 \\
\hline Large vessel occlusion & $22(100 \%)$ & $55(74 \%)$ & 0.01 \\
\hline Recanalization $(\mathrm{n}=53)$ & $9 / 17(53 \%)$ & $12 / 36(33 \%)$ & 0.23 \\
\hline \multicolumn{4}{|l|}{ Treatment modalities } \\
\hline Mechanical thrombectomy ${ }^{\mathrm{a}}$ & $9(41 \%)$ & $11(15 \%)$ & 0.013 \\
\hline IV thrombolysis & $9(41 \%)$ & $32(44 \%)$ & 0.50 \\
\hline IA thrombolysis & 0 & $3(4 \%)$ & 0.45 \\
\hline
\end{tabular}

a Comparison of imaging and clinical characteristics between ischemic stroke patients with and without hemorrhagic transformation. NIHSS = National Institute of Health Stroke Scale; rCBF = relative cerebral blood flow; $\mathrm{rCBV}=$ relative cerebral blood volume; rMTT = relative mean transit time; rPS = relative permeability surface area product; IV = intravenous; IA = intra-arterial.

average of $1.9 \mathrm{~h}$ later for those with than for those without HT $(4.9 \pm 1.8$ vs. $3.0 \pm 2.4 \mathrm{~h}, \mathrm{p}=0.075)$. Importantly, for the subset of patients who underwent mechanical thrombectomy with HT, time from ictus to recanalization was significantly longer than for those without HT $(8.7 \pm 1.4$ vs. $6.2 \pm 1.7 \mathrm{~h}, \mathrm{p}=0.006$ ).

ROC curve analysis showed an AUC $=0.75, \mathrm{p}<0.01$ for the admission NIHSS score determination of HT. An admission NIHSS score $<10$ had a negative predictive value (NPV) of $100 \%(n=32,9$ of whom were treated with IV lysis) for HT.

A binary logistic regression, using as inputs admission NIHSS, mechanical thrombectomy, and all of the CTPbased imaging variables that were significant in the univariate analysis (table 3 ), revealed only the two independent predictors of HT: (1) mean rMTT within the rMTT $>1.3$ segmented lesion (OR 3.7, p = 0.007), and (2) mechanical thrombectomy (OR 3.7, $\mathrm{p}=0.025)$. Figure 1 shows a sample case.

When patients were stratified according to time postictus at admission (early $=\leq 4.5 \mathrm{~h}$ post-ictus, late $=$
$>4.5 \mathrm{~h}$ post-ictus), NIHSS was the only independent predictor of HT in those admitted early (OR 1.2, $\mathrm{p}=0.015)$, whereas both (1) mechanical thrombectomy (OR 4.3, p = 0.048 ) and (2) the mean rMTT within the MTT-segmented lesion (OR 2.5, $\mathrm{p}=0.08$ ) were the independent predictors in those admitted beyond $4.5 \mathrm{~h}$.

\section{Discussion}

Our study has confirmed that the extent and degree of hemodynamic derangement in acute stroke patients can help identify those at highest risk for HT, and, more importantly, has shown that the detection of such severely ischemic tissue can be accomplished using CTP imaging with similar accuracy to that of DWI. These results suggest that CTP may have added value in the evaluation of acute stroke patients when MRI is not available or contraindicated.

Specifically, admission CTP CBF and MTT ischemic lesion volumes - relative thresholds of $\mathrm{rCBF}<0.48$ and 


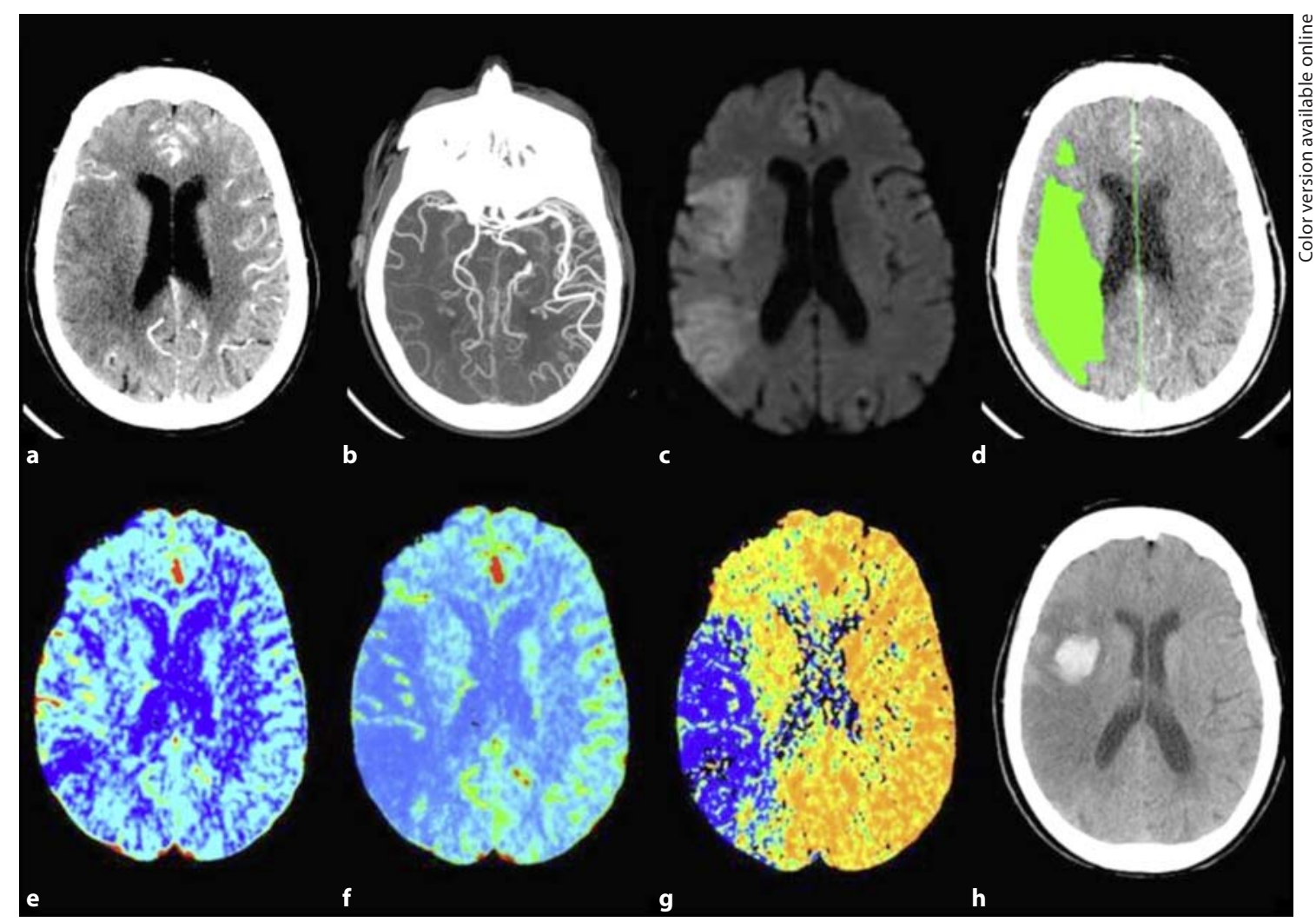

Fig. 1. An 81-year-old female presenting $6 \mathrm{~h}$ after the onset of leftsided weakness and right gaze preference; not a candidate for endovascular therapy: a 5-mm thick CTA source image shows poor tissue opacification of the right MCA territory, $\mathbf{b}$ CTA maximum intensity projection image shows proximal right MCA occlusion with poor collateralization, $\mathbf{c}$ DWI shows right MCA territory infarct core, $\mathbf{d}$ thresholded MTT lesion (rMTT >1.3), with $140 \mathrm{ml}$ total volume, e CBV map shows relative hyperemia (increased blood volume) of the cortical right MCA territory, f CBF map show decreased flow of the right MCA territory, corresponding to the DWI lesion, $\mathbf{g}$ MTT map shows corresponding area of prolonged transit time in the right MCA territory, mean $\mathrm{rMTT}=4.3$, and $\mathbf{h} 24 \mathrm{~h}$ follow-up NCCT shows HT at the anterior right MCA territory.
rMTT $>1.3$ - are strongly associated with HT. Indeed, the admission MTT lesion volumes showed a trend towards being slightly more accurate than the admission DWI lesion volumes in determining HT in our cohort, although this difference was not significant. These findings are in agreement with the concept that HT is a consequence of severe ischemic damage to vessel walls that leads to bloodbrain barrier disruption and leakage [15]. CTP may better express the degree of ischemia associated with intense vessel wall damage than DWI, and hence have the potential to correlate more strongly with the development of HT. Our findings are supported by other studies that have reported reduced pretreatment $\mathrm{CBF}$ as a predictor of HT $[7,8]$.

Permeability surface area product maps are intended to reflect the degree of blood-brain barrier leakage, and although they have been shown to correlate with HT [3-
5], they are potentially fraught with substantial variability due to differences in acquisition and post-processing technique, including the size and molecular charge of the contrast agent used [16]. In our study, we hypothesize that the absence of correlation between rPS and HT can be attributed to our relatively short CTP acquisition protocol of 90 s. PS maps are typically calculated from CTP studies with acquisition times considerably over $120 \mathrm{~s}$, to allow contrast sufficient time to leak into the interstitium.

Presence of a LVO was strongly associated with HT. As already noted, the degree of ischemia may play a role in small vessel friability, especially in the setting of maximal autoregulatory vasodilatation of the collateral bed. Because the number of patients in each subgroup was small, we did not reveal an association between HT and either recanalization or treatment with IV or IA thrombolysis. For those patients who received both IA thrombolysis 
and mechanical thrombectomy, however, there was a strong association between HT and treatment, but importantly only for those treated after $4.5 \mathrm{~h}$ post-ictus (i.e. those with late recanalization). The correlation between recanalization and HT has been previously noted and is thought to reflect the fact that there needs to be some degree of reperfusion for bleeding to occur, although this point remains controversial $[1,17]$. It may be that it is not recanalization per se, but rather late recanalization, which is a risk factor for HT [2, 15, 18, 19]. As discussed above, potential bleeding sources not only include the oligemic recanalized tissue bed, but also the flow augmented collateral vasculature [20]. Some authors have reported that good collateral circulation is associated with less severe blood-brain barrier disruption, and consequently a lower incidence of HT [21].

Admission NIHSS scores were significantly higher in the HT patients. In this regard, the NIHSS score may function as a marker of 'clinical penumbra', as the functional disabilities attributable to ischemia of eloquent cortex are believed to correlate with large volumes of severe flow derangement, as suggested by the $\mathrm{CBF}$ and MTT maps.

Our study has many limitations, arguably the most important of which was an insufficient number of patients with HT to stratify into symptomatic versus asymptomatic groups, or $\mathrm{PH}$ versus $\mathrm{HI}$ groups. Ours also has all the limitations and potential biases inherent with a retrospective study, especially with regard to the relationship between HT and treatment, as the risk of hemorrhage was almost certainly considered when excluding both the most and least ill patients from thrombolytic or endovascular therapies. Of note, our PS maps likely failed to show a correlation with HT due to an insufficiently long acquisition time to accurately measure this parameter; many centers which perform CTP have similarly short acquisition times, especially given recent concerns regarding CTP radiation dose.

In conclusion, the associations that we have shown between HT of acute stroke and the volume/degree of admission ischemia support those of previous studies, can be accurately estimated using CT scanning only (both CTA and CTP) if DWI cannot be performed, and may be of modest clinical relevance - especially for their NPV in identifying patients (with low admission NIHSS scores, no LVO, and small admission ischemic lesions) at minimal risk for HT. Finally, although our retrospective pilot model suggests that late mechanical thrombolysis may be an independent risk factor for HT, this needs to be prospectively validated in a larger cohort of patients.

\section{Acknowledgements}

This work was supported by the Specialized Programs of Translational Research in Acute Stroke (SPOTRIAS) Network grant funded by the National Institute of Health (NIH; P50 NS051343), the Agency for Healthcare Research and Quality grant AHRQ R01 HS11392, and the Massachusetts General Hospital Clinical Research Center (No. 1 UL1 RR025758-01) Harvard Clinical and Translational Science Center, from the National Center for Research Resources.

\section{Disclosure Statement}

M.H.L. receives research support from GE Healthcare, and is a consultant to Co-Axia, GE Healthcare, and Millennium Pharmaceuticals.

\section{References}

1 Selim M, Fink JN, Kumar S, Caplan LR, Horkan C, Chen Y, Linfante I, Schlaug G: Predictors of hemorrhagic transformation after intravenous recombinant tissue plasminogen activator: prognostic value of the initial apparent diffusion coefficient and diffusionweighted lesion volume. Stroke 2002;33: 2047-2052.

- 2 Puetz V, Dzialowski I, Hill MD, Subramaniam S, Sylaja PN, Krol A, O’Reilly C, Hudon ME, Hu WY, Coutts SB, Barber PA, Watson T, Roy J, Demchuk AM: Intracranial thrombus extent predicts clinical outcome, final infarct size and hemorrhagic transformation in ischemic stroke: the clot burden score. Int J Stroke 2008;3:230-236.
-3 Aviv RI, d'Esterre CD, Murphy BD, Hopyan JJ, Buck B, Mallia G, Li V, Zhang L, Symons SP, Lee TY: Hemorrhagic transformation of ischemic stroke: prediction with CT perfusion. Radiology 2009;250:867-877.

- 4 Kassner A, Roberts TP, Moran B, Silver FL, Mikulis DJ: Recombinant tissue plasminogen activator increases blood-brain barrier disruption in acute ischemic stroke: an MR imaging permeability study. AJNR Am J Neuroradiol 2009;30:1864-1869.
5 Hom J, Dankbaar JW, Soares BP, Schneider T, Cheng SC, Bredno J, Lau BC, Smith W, Dillon WP, Wintermark M: Blood-brain barrier permeability assessed by perfusion CT predicts symptomatic hemorrhagic transformation and malignant edema in acute ischemic stroke. AJNR Am J Neuroradiol 2011;32:41-48.

6 Kidwell CS, Latour L, Saver JL, Alger JR, Starkman S, Duckwiler G, Jahan R, Vinuela F, Kang DW, Warach S: Thrombolytic toxicity: blood-brain barrier disruption in human ischemic stroke. Cerebrovasc Dis 2008;25: 338-343. 
7 Campbell BC, Christensen S, Butcher KS, Gordon I, Parsons MW, Desmond PM, Barber PA, Levi CR, Bladin CF, De Silva DA, Donnan GA, Davis SM: Regional very low cerebral blood volume predicts hemorrhagic transformation better than diffusionweighted imaging volume and thresholded apparent diffusion coefficient in acute ischemic stroke. Stroke 2010;41:82-88.

8 Gupta R, Yonas H, Gebel J, Goldstein S, Horowitz M, Grahovac SZ, Wechsler LR, Hammer MD, Uchino K, Jovin TG: Reduced pretreatment ipsilateral middle cerebral artery cerebral blood flow is predictive of symptomatic hemorrhage post-intra-arterial thrombolysis in patients with middle cerebral artery occlusion. Stroke 2006;37:25262530.

$\checkmark 9$ Schaefer PW, Copen WA, Lev MH, Gonzalez RG: Diffusion-weighted imaging in acute stroke. Magn Reson Imaging Clin N Am 2006;14:141-168.

- 10 Ueda T, Hatakeyama T, Kumon Y, Sakaki S, Uraoka T: Evaluation of risk of hemorrhagic transformation in local intra-arterial thrombolysis in acute ischemic stroke by initial SPECT. Stroke 1994;25:298-303.

- 11 Alsop DC, Makovetskaya E, Kumar S, Selim M, Schlaug G: Markedly reduced apparent blood volume on bolus contrast magnetic resonance imaging as a predictor of hemorrhage after thrombolytic therapy for acute ischemic stroke. Stroke 2005;36:746-750.
12 http://www2.Massgeneral.Org/stopstroke/ protocoliviathrom.Aspx.

13 Torres-Mozqueda F, He J, Yeh IB, Schwamm LH, Lev MH, Schaefer PW, Gonzalez RG: An acute ischemic stroke classification instrument that includes CT or MR angiography: The Boston Acute Stroke Imaging Scale. AJNR Am J Neuroradiol 2008;29:1111-1117.

-14 Fiorelli M, Bastianello S, von Kummer R, del Zoppo GJ, Larrue V, Lesaffre E, Ringleb AP, Lorenzano S, Manelfe C, Bozzao L: Hemorrhagic transformation within 36 hours of a cerebral infarct: relationships with early clinical deterioration and 3-month outcome in the European Cooperative Acute Stroke Study I (ECASS I) cohort. Stroke 1999;30 2280-2284.

15 Khatri P, Wechsler LR, Broderick JP: Intracranial hemorrhage associated with revascularization therapies. Stroke 2007;38:431440.

16 Sorensen AG: Science to practice: bloodbrain barrier leakage - one size does not fit all. Radiology 2010;257:303-304.
17 Fiehler J, Remmele C, Kucinski T, Rosenkranz M, Thomalla G, Weiller C, Zeumer H, Rother J: Reperfusion after severe local perfusion deficit precedes hemorrhagic transformation: an MRI study in acute stroke patients. Cerebrovasc Dis 2005;19:117-124.

18 Hacke W, Kaste M, Fieschi C, Toni D, Lesaffre E, von Kummer R, Boysen G, Bluhmki E, Hoxter G, Mahagne MH, et al: Intravenous thrombolysis with recombinant tissue plasminogen activator for acute hemispheric stroke. The European Cooperative Acute Stroke Study (ECASS). JAMA 1995;274: 1017-1025.

19 Lansberg MG, Albers GW, Wijman CA: Symptomatic intracerebral hemorrhage following thrombolytic therapy for acute ischemic stroke: a review of the risk factors. Cerebrovasc Dis 2007;24:1-10.

20 Del Zoppo GJ, von Kummer R, Hamann GF: Ischaemic damage of brain microvessels: inherent risks for thrombolytic treatment in stroke. J Neurol Neurosurg Psychiatry 1998; 65:1-9.

-21 Dankbaar JW, Hom J, Schneider T, Cheng SC, Bredno J, Lau BC, van der Schaaf IC, Wintermark M: Dynamic perfusion-CT assessment of early changes in blood-brain barrier permeability of acute ischaemic stroke patients. J Neuroradiol 2011;38:161166. 